\title{
Carinal resection and reconstruction with complete pulmonary parenchyma preservation: a single-institution analysis of $\mathbf{3 6}$ cases
}

\author{
Liang Chen ${ }^{1 *}$, Zhexin Wang ${ }^{1 *}$, Heng Zhao $^{1}$, Giulio Maurizi ${ }^{2}$, Takuro Miyazaki ${ }^{3}$, Ryuichi Waseda ${ }^{4}$, Feng Yao ${ }^{1}$ \\ ${ }^{1}$ Department of Thoracic Surgery, Shanghai Chest Hospital, Shanghai Jiao Tong University, Shanghai, China; ${ }^{2}$ Division of Thoracic Surgery, \\ Sant'Andrea Hospital, Sapienza University of Rome, Rome, Italy; ${ }^{3}$ Department of Surgical Oncology, Nagasaki University Graduate School of \\ Biomedical Sciences, Nagasaki, Japan; ${ }^{4}$ Department of General Thoracic, Breast, and Pediatric Surgery, Fukuoka University, Jonan-ku, Fukuoka, \\ Japan \\ Contributions: (I) Conception and design: F Yao; (II) Administrative support: None; (III) Provision of study materials or patients: H Zhao, F Yao; \\ (IV) Collection and assembly of data: L Chen, Z Wang; (V) Data analysis and interpretation: L Chen, Z Wang, F Yao; (VI) Manuscript writing: All \\ authors; (VII) Final approval of manuscript: All authors. \\ \#These authors contributed equally to this work. \\ Correspondence to: Feng Yao, MD. Department of Thoracic Surgery, Shanghai Chest Hospital, Shanghai Jiao Tong University, 241 Huaihai Road \\ West, Shanghai 200030, China. Email: yaofeng6796678@126.com.
}

Background: Carinal resection, performed in only a few high-volume centers, remains one of the most complicated and technically demanding surgeries. Few studies have examined the outcomes of carinal resection and reconstruction with complete pulmonary parenchyma preservation.

Methods: Patients who underwent isolated carinal resection and reconstruction at the Shanghai Chest Hospital between 2006 and 2020 were retrospectively reviewed. Clinicopathological, perioperative, and follow-up outcomes were analyzed.

Results: A total of 36 patients were included, including 19 men and 17 women. The average age was $50.7 \pm 14.8$ years. Right posterolateral thoracotomy $(n=33,91.7 \%)$ and cross-field intubation during anastomosis $(n=31,86.1 \%)$ were selected for the majority of the carinal surgeries. The average intraoperative blood loss was $225.0 \mathrm{~mL}$, and the mean operation duration was 196.1 minutes. Postoperative complications were observed in 14 patients (38.9\%), including cicatricial stenosis $(n=8,22.2 \%)$, anastomotic fistula ( $n=3$, $8.3 \%)$, air leak $(n=1,2.8 \%)$, cardiac arrhythmia $(n=4,11.1 \%)$, pneumonia $(n=2,5.6 \%)$, respiratory failure $(\mathrm{n}=1,2.8 \%)$, and pulmonary embolism $(\mathrm{n}=1,2.8 \%)$. There were 2 perioperative deaths $(5.6 \%)$. Multivariate analysis revealed that being overweight was an independent favorable factor for postoperative complications $[\mathrm{P}=0.042$, odds ratio $(\mathrm{OR})=0.092,95 \%$, confidence interval (CI): 0.009-0.922]. Pathological diagnoses included squamous cell carcinoma (SCC) ( $\mathrm{n}=12,33.3 \%)$, adenoid cystic carcinoma (ACC) ( $\mathrm{n}=15,41.7 \%)$, mucoepidermoid carcinoma (MEC) $(n=2,5.6 \%)$, stricture $(n=1,2.8 \%)$, and other rare histological types. An R0 resection was achieved in 14 patients, while 21 patients $(60.0 \%)$ had microscopically positive margins. Lymph node metastasis was confirmed in 6 patients (17.1\%). Overall survival (OS) was $94.4 \%$ at 1 year and $79.4 \%$ at 5 years, with 107 months as the median survival time (95\% CI: 64.0-150.0 months). All patients with negative margins remained alive during the follow-up period, while those who received R1 resections had much poorer survival rates due to tumor recurrence $[\mathrm{P}=0.042$, hazard ratio $(\mathrm{HR})=4.938,95 \%$ CI: $1.062-$ 22.950].

Conclusions: In selected patients, carinal resection and reconstruction with complete pulmonary parenchyma preservation was a feasible option to achieve an appreciable long-term survival at the risk of acceptable operative mortality and morbidity, particularly when complete resection with negative margins could be realized.

Keywords: Carinal resection; carinal reconstruction; carinal tumor 
Submitted Aug 19, 2021. Accepted for publication Dec 20, 2021.

doi: $10.21037 /$ tlcr-21-937

View this article at: https://dx.doi.org/10.21037/tlcr-21-937

\section{Introduction}

For tumors invading the lower trachea or carina and inflammatory stenosis, carinal resection and reconstruction helps improve the prognosis as the curative or palliative surgical treatment (1-5). With high technical difficulties and perioperative risks, it remains one of the most challenging thoracic surgeries, carried out in only a few high-volume centers worldwide. Several recent studies have revealed that with advances in anesthesia and surgical techniques (6), carinal resection and reconstruction with acceptable operative mortality and morbidity is feasible for carefully selected patients (7-9). However, most of these results were based on a relatively small sample size. Further, most previously reported cases involved carinal resection combined with different degrees of pulmonary resection, such as carinal sleeve lobectomy or carinal sleeve pneumonectomy, rather than carinal resection and reconstruction with complete pulmonary parenchyma preservation (10-12).

Considering that concomitant pulmonary resection during carinal resection has been reported to increase the incidence of postoperative complications (13), we aimed to investigate and evaluate the short-term and long-term outcomes of carinal resection and reconstruction with complete pulmonary parenchyma preservation. We present the following article in accordance with the STROBE reporting checklist (available at https://dx.doi.org/10.21037/ tlcr-21-937).

\section{Methods}

\section{Patients}

Patients who underwent carinal resection and reconstruction with complete pulmonary parenchyma preservation at Shanghai Chest Hospital were retrospectively reviewed. The study was conducted in accordance with the Declaration of Helsinki (as revised in 2013). The study was approved by the ethics board of Shanghai Chest Hospital (ethics approval: KS1992) and individual consent for this retrospective analysis was waived. The indications for carinal resection and reconstruction with complete pulmonary parenchyma preservation were lesions confined to the carina or carinal lesions involving the lower trachea, including tracheobronchial neoplasms, stricture, or inflammatory disease $(14,15)$. Patients with severe comorbidities, extensive tumor invasion, clinical N2 diseases or greater were considered as relative or absolute contraindications (16). Meticulous multidisciplinary preoperative assessments were carried out by expert thoracic surgeons and anesthesiologists, including comorbidity evaluation and clinical staging through computed tomography (CT) scan, brain magnetic resonance imaging (MRI), positron emission tomography (PET), and bronchoscopy. The clinicopathological, perioperative, and follow-up outcomes were then collected and analyzed.

\section{Surgical techniques}

During the operation, anesthesia was managed by dedicated thoracic anesthesiologists. Surgical approaches were selected on the basis of the location and extent of the tumor, including posterolateral thoracotomy, median sternotomy (17), or minimally invasive surgery attempted by experienced surgeons (18). Ventilation strategies employed during anastomosis included cross-field ventilation using endotracheal intubation, high-frequency jet ventilation (HFJV), and extracorporeal membrane oxygenation (ECMO). After removal of the carina, additional resections were necessary if positive margins were confirmed by frozen-section analysis. Anastomotic tension was reduced using several methods, including neck flexion when performing the anastomosis, hilar release, and division of the inferior pulmonary ligament $(16,19)$. Based on the extent of resection and anastomotic tension, 4 different carinal reconstruction methods were used to reconstruct the neocarina (tracheobronchial bifurcation) (Figure 1). For lesions confined to the carina, the medial walls of the right main bronchus (RMB) and left main bronchus (LMB) were sutured together, and then the trachea was anastomosed end-to-end to the new bronchial bifurcation (double-barrel reconstruction, Figure 1A) (20). For carinal lesions involving the lower trachea, the neocarina was reconstructed using the following techniques. When the length of resected airway was generally less than $4 \mathrm{~cm}$, the trachea was anastomosed end-to-end to the $\mathrm{LMB}$, and the RMB was 

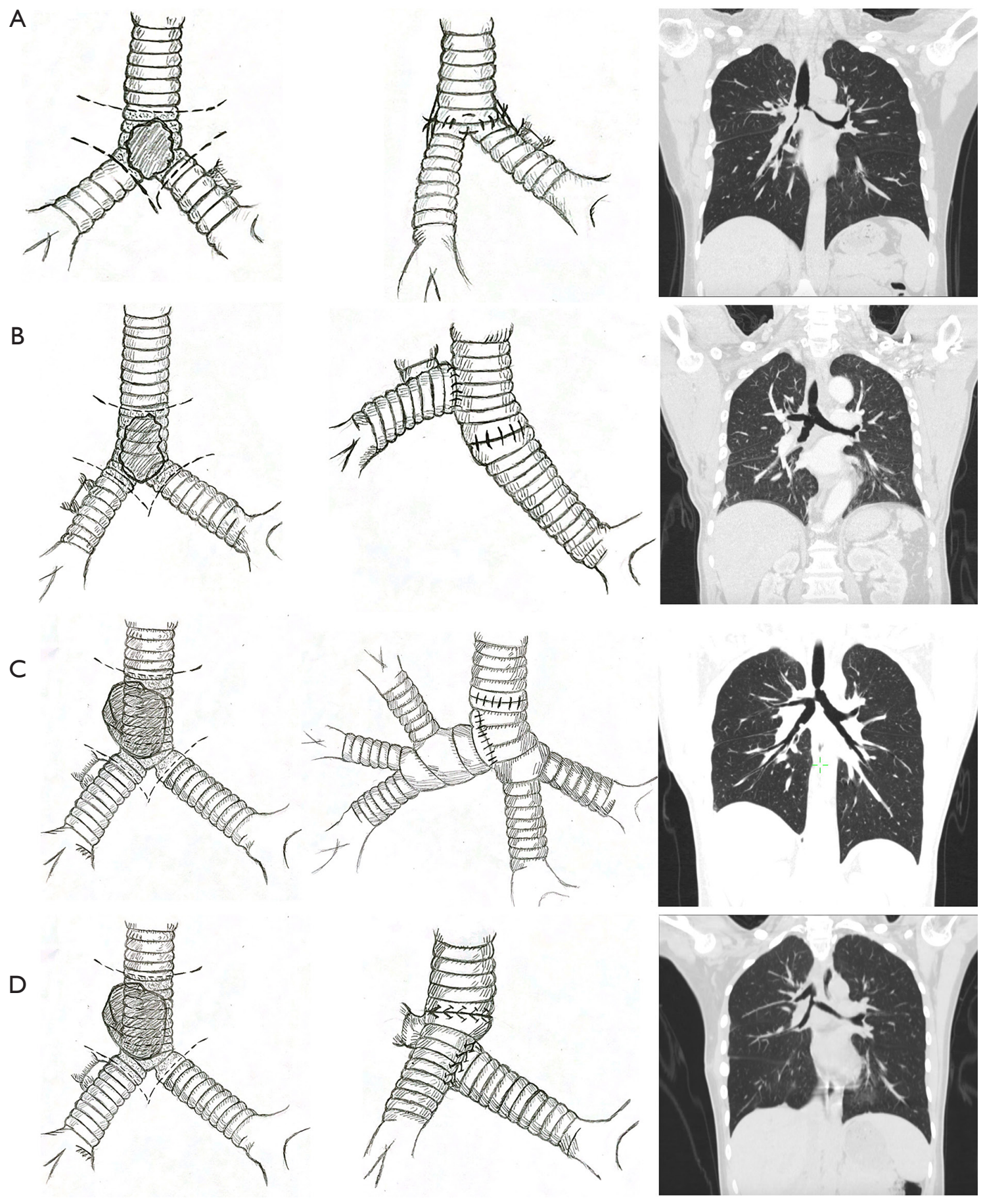

Figure 1 Four types of carinal reconstruction were performed in this study. Postoperative computed tomography images in the frontal plane are shown for each reconstruction type as follows: (A) the trachea was anastomosed end-to-end to the newly reconstructed carina after suturing the RMB and LMB together (double-barrel reconstruction, $\mathrm{n}=4$ ); (B,C) the trachea was anastomosed end-to-end to the LMB, and then the RMB was anastomosed end-to-side to the trachea above the first anastomosis (first type of Eschapasse reconstruction, $\mathrm{n}=21$ ) or to the LMB below the first anastomosis (second type of Eschapasse reconstruction, $n=2$ ); and (D) the RMB was anastomosed to the end of the trachea and the LMB was anastomosed end-to-side to the intermedius (Barclay reconstruction, $\mathrm{n}=9$ ). RMB, right main bronchus; LMB, left main bronchus. 
then anastomosed end-to-side to the trachea above the first anastomosis (first type of Eschapasse reconstruction, Figure $1 B$ ) or to the LMB below the first anastomosis (second type of Eschapasse reconstruction, Figure 1C). Otherwise, the RMB was anastomosed to the end of the trachea and the LMB was anastomosed end-to-side to the intermedius (Barclay reconstruction, Figure 1D) (15). After the anastomosis was completed, airtightness was checked with an inflation pressure of $30 \mathrm{~cm}$ of water and inspected intraoperatively by bronchoscopy. To potentially prevent the anastomotic fistula, the anastomotic site was covered by vascular pedicled intercostal muscles, pleural flaps, thymus tissues, or fibrin glue $(19,21,22)$.

\section{Postoperative management}

After surgery, all patients were rigorously required to maintain neck flexion by the guardian chin suture and supporting pillows for at least 2 weeks. The patients were encouraged to become ambulatory and do respiratory function training. Inhalation of low flow oxygen, prophylactic use of antibiotics, aerosol, and expectorant was applied postoperatively. Bronchoscopy might be performed for secretion management and check up of the anastomotic site. In general, the adjuvant therapy including chemotherapy or radiotherapy was administered for patients with positive resected margins or lymph nodes about 4-6 weeks after the surgery.

\section{Follow-up}

Postoperative surveillance included physical examination, laboratory tests, chest CT scan, and abdominal ultrasound examination performed at 1 month after surgery, every 6 months during the following 5 years, and then annually. Bronchoscopy was conducted at 6 months and 1 year after surgery, and annually thereafter for patients with malignant tumors, or indefinitely if the patient had any complaints. $\mathrm{PET} / \mathrm{CT}$ and brain MRI were performed if recurrence or progression was suspected. All follow-up data was collected from the outpatient system or by telephone calls.

\section{Statistical analysis}

Continuous variables are expressed as mean \pm standard deviation or median with range depending on the normality of distribution. Categorical variables are expressed as count with proportion. The predictors of postoperative complications were evaluated by binary logistic regression model. Variables with $\mathrm{P}$ value $\leq 0.2$ after univariate analysis were included in multivariate logistic regression. Results are reported as odds ratio (OR) with a $95 \%$ confidence interval (95\% CI). The Kaplan-Meier method was used to estimate overall survival (OS), which was defined as the time from the date of surgery until the last date of follow-up for patients who remained alive or until death from any cause. The hazard ratio (HR) of survival was assessed by Cox regression and presented with a $95 \%$ CI. All $\mathrm{P}$ values were 2 -sided and $\mathrm{P}$ values below 0.05 were considered significant. Statistical analyses were performed by SPSS v26.0 software and GraphPad Prism 8.2 software was used to produce graphics.

\section{Results}

A total of 36 patients from 2006 to 2020 were included in this retrospective study (19 men and 17 women). The mean age was 50.7 years, ranging from 13 to 71 years (Table 1). According to the World Health Organization classification (23), there were 2 underweight patients $\left(<18.5 \mathrm{~kg} / \mathrm{m}^{2}, 5.6 \%\right), 23$ patients of normal weight $\left(18.5-25 \mathrm{~kg} / \mathrm{m}^{2}, 63.9 \%\right)$, and 11 overweight patients $(25$ $\left.-30 \mathrm{~kg} / \mathrm{m}^{2}, 30.6 \%\right)$. Eleven patients $(30.6 \%)$ were former or current smokers. Preoperative comorbidities were found in 11 patients $(30.6 \%)$, including hypertension $(\mathrm{n}=7,19.4 \%)$, diabetes $(\mathrm{n}=1,2.8 \%)$, coronary heart disease $(\mathrm{n}=1,2.8 \%)$, cerebral infarction $(\mathrm{n}=3,8.3 \%)$, and deep vein thrombosis $(n=1,2.8 \%)$. Four patients $(11.1 \%)$ had received thoracoscopic lobectomies for lung cancer before admission. Obstructive pneumonia or atelectasis was observed in preoperative CT images for 6 patients (16.7\%). Before surgery, 3 patients ( $8.3 \%$ ) had received endoscopic treatments for the carinal lesions, including electric burn $(\mathrm{n}=2,5.6 \%)$ and snare excision $(\mathrm{n}=1,2.8 \%)$.

Most of the carinal surgeries in this study $(n=33$, $91.7 \%$ ) were performed through right posterolateral thoracotomy. In addition, there was 1 case of roboticassisted thoracoscopic surgery (18) and 2 cases of median sternotomy (Table 2). In most cases $(\mathrm{n}=31$, $86.1 \%$ ), conventional cross-field intubation was applied during anastomosis. HFJV was used in 1 case $(2.8 \%)$ and venovenous ECMO (VV-ECMO) was used for 4 patients $(11.1 \%)$ due to failure of single lung ventilation maintenance or an emergency situation. Four patients received the double-barrel reconstruction $(11.1 \%), 21$ received the first type of Eschapasse reconstruction (58.3\%), 
Table 1 The demographic characteristics of patients receiving carinal resection and reconstruction with complete pulmonary parenchyma preservation

\begin{tabular}{|c|c|}
\hline Variables & Overall $(n=36)$ \\
\hline \multicolumn{2}{|l|}{ Sex } \\
\hline Male & $19(52.8)$ \\
\hline Female & $17(47.2)$ \\
\hline Age (year) & $50.7 \pm 14.8$ \\
\hline \multicolumn{2}{|l|}{ BMI $\left(k g / m^{2}\right)$} \\
\hline Underweight & $2(5.6)$ \\
\hline Normal weight & $23(63.9)$ \\
\hline Overweight & $11(30.6)$ \\
\hline \multicolumn{2}{|l|}{ Smoking history } \\
\hline Never smoked & $25(69.4)$ \\
\hline Former smoker & $11(30.6)$ \\
\hline Comorbidity & $11(30.6)$ \\
\hline Hypertension & $7(19.4)$ \\
\hline Diabetes & $1(2.8)$ \\
\hline Coronary heart disease & $1(2.8)$ \\
\hline Cerebral infarction & $3(8.3)$ \\
\hline Deep vein thrombosis & $1(2.8)$ \\
\hline Previous lung surgery & $4(11.1)$ \\
\hline Right middle lobectomy & $1(2.8)$ \\
\hline Right lower lobectomy & $1(2.8)$ \\
\hline Left upper lobectomy & $1(2.8)$ \\
\hline Left lower lobectomy & $1(2.8)$ \\
\hline $\begin{array}{l}\text { Obstructive pneumonia or atelectasis in CT } \\
\text { images }\end{array}$ & $6(16.7)$ \\
\hline Preoperative endoscopic treatment & $3(8.3)$ \\
\hline Electric burn & $2(5.6)$ \\
\hline Snare excision & $1(2.8)$ \\
\hline
\end{tabular}

Values are presented as $n(\%)$ or mean \pm standard deviation. $\mathrm{BMI}$, body mass index; CT, computed tomography.

2 received the second type of Eschapasse reconstruction (5.6\%), and 9 received Barclay reconstruction (25.0\%). The average intraoperative blood loss was $225.0 \mathrm{~mL}$, and the mean operation duration was 196.1 minutes.

Major and minor postoperative complications were observed in 14 patients (38.9\%, Table 3). Among them,
Table 2 Surgical characteristics of patients receiving carinal resection and reconstruction with complete pulmonary parenchyma preservation

\begin{tabular}{lc}
\hline Variables & Overall $(\mathrm{n}=36)$ \\
\hline Surgical approach & \\
Minimally invasive surgery & $1(2.8)$ \\
Posterolateral thoracotomy & $33(91.7)$ \\
Median sternotomy & $2(5.6)$ \\
Ventilation strategy & \\
Cross-field intubation & $31(86.1)$ \\
HFJV & $1(2.8)$ \\
ECMO & $4(11.1)$
\end{tabular}

Type of reconstruction

Double-barrel reconstruction

First type of Eschapasse reconstruction

$21(58.3)$

Second type of Eschapasse reconstruction

Barclay reconstruction

$9(25.0)$

Release of hilar or ligament

Anastomosis wrapped

Blood loss $(\mathrm{mL})$

$225.0 \pm 118.0$

Operation duration (min)

$196.1 \pm 63.5$

Values are presented as $\mathrm{n}(\%)$ or mean \pm standard deviation. HFJV, high-frequency jet ventilation; ECMO, extracorporeal membrane oxygenation.

10 patients experienced technique-related complications, including cicatricial stenosis $(\mathrm{n}=8,22.2 \%$; 4 patients were treated with stent implantation and 4 were treated with balloon dilatation), anastomotic fistula $(n=3,8.3 \%$; all treated by conservative therapy), and moderate air leak ( $\mathrm{n}=1,2.8 \%$; due to the pleural adhesion). The anastomosisrelated events (cicatricial stenosis and anastomotic fistula) occurred in 1 case of the double-barrel reconstruction, 5 cases of the first type of Eschapasse reconstruction, 1 case of the second type of Eschapasse reconstruction, and 2 cases of Barclay reconstruction. The incidence of anastomosisrelated events was lower in the double-barrel reconstruction and the first type of Eschapasse reconstruction (both main bronchi were anastomosed with the trachea) compared to the second type of Eschapasse reconstruction and Barclay reconstruction (the end-to-side anastomoses might be limited by the diameter of main bronchus or intermedius). 
Table 3 Postoperative course of patients receiving carinal resection and reconstruction with complete pulmonary parenchyma preservation

\begin{tabular}{lc}
\hline Variables & Overall $(\mathrm{n}=36)$ \\
\hline Operative mortality & $2(5.6)$ \\
Operative complications & $14(38.9)$ \\
Technique-related complications & $10(27.8)$ \\
Anastomosis-related complications & $9(25.0)$ \\
$\quad$ Anastomotic fistula & $3(8.3)$ \\
$\quad$ Cicatricial stenosis & $8(22.2)$ \\
Air leak & $1(2.8)$ \\
Cardiopulmonary complications & $5(13.9)$ \\
Cardiac arrhythmia & $4(11.1)$ \\
Pneumonia & $2(5.6)$ \\
Respiratory failure & $1(2.8)$ \\
Pulmonary embolism & $1(2.8)$ \\
Duration of chest tube drainage (days) & $7[4-28]$ \\
Length of hospital stay (days) & $11[7-46]$ \\
\hline
\end{tabular}

Values are presented as $\mathrm{n}(\%)$ or median [range].

However, no significant difference was observed (27.3\% vs. $24 \%, \mathrm{P}=0.835)$. Five patients suffered cardiopulmonary complications, including cardiac arrhythmia $(\mathrm{n}=4,11.1 \%)$, pneumonia $(\mathrm{n}=2,5.6 \%)$, respiratory failure $(\mathrm{n}=1,2.8 \%)$, and pulmonary embolism $(\mathrm{n}=1,2.8 \%)$. Two perioperative deaths occurred $(5.6 \%)$; 1 patient died of respiratory failure following pulmonary embolism, and the other patient suffered sudden and serious ventricular fibrillation. Univariate and multivariate analysis indicated that body mass index (BMI) was the only variable associated with the incidence of postoperative events and being overweight was identified as an independent favorable factor for postoperative complications $(\mathrm{P}=0.042, \mathrm{OR}=0.092,95 \%$ CI: 0.009-0.922, Table 4).

Final pathological examination confirmed 12 cases of squamous cell carcinoma (SCC, 33.3\%), 15 cases of adenoid cystic carcinoma (ACC, 41.7\%), 2 cases of mucoepidermoid carcinoma (MEC, 5.6\%), 1 case of stricture, and 5 other rare histological types (Table 5). R0 resections were achieved in 14 patients (40.0\%), while for 21 patients $(60.0 \%)$, resected margins were microscopically positive, including 5 patients with SCC, 13 patients with ACC, and 3 patients with other histological types (MEC, inflammatory myofibroblastic tumor, and atypical hyperplasia, respectively). The average length of resected airway was $3.2 \mathrm{~cm}$, ranging from 1.0 to $5.5 \mathrm{~cm}$. No significant difference was detected in the length of resected airway between $\mathrm{R} 0$ and $\mathrm{R} 1$ resections $(\mathrm{P}=0.559)$. Lymph node metastasis was confirmed in 6 cases $(17.1 \%)$, including 2 patients with $\mathrm{N} 1$ metastasis caused by ACC and SCC, respectively, and 4 patients with N2 metastasis caused by SCC.

After surgery, 12 patients (33.3\%) received postoperative radiotherapy or chemotherapy due to positive margins or lymph node metastasis. OS in this study was $94.4 \%$ at 1 year and $79.4 \%$ at 5 years, with 107 months as the median survival time (95\% CI: 64.0-150.0 months, Figure 2) and 32.5 months as the median follow-up time (range, 0.37 -159 months). All patients with negative margins remained alive during the follow-up period, while those who received $\mathrm{R} 1$ resections had much poorer outcomes due to tumor recurrence (5-year OS: $100 \%$ vs. $68.9 \%, \mathrm{P}=0.042$, HR $=4.938,95 \%$ CI: $1.062-22.950$, Figure $3 A$ ). No significant difference was detected in survival between patients with SCC and non-SCC (5-year OS: $83.3 \%$ vs. $80.8 \%, \mathrm{P}=0.127$, $\mathrm{HR}=3.320,95 \%$ CI: 0.652-16.902, Figure 3B) or between patients with positive and negative lymph nodes (5-year OS: $83.3 \%$ vs. $79.7 \%, \mathrm{P}=0.647$, HR $=1.675,95$ \% CI: 0.185 $15.178)$.

\section{Discussion}

Due to the technical difficulties and high perioperative risks, carinal resection and reconstruction is regarded as one of the most complicated thoracic surgeries, performed in only a few centers worldwide. Previous studies have reported perioperative and survival outcomes of carinal resection combined with different degrees of lung resection (7-9). For lesions confined to the carina or carinal lesions involving the lower trachea, isolated carinal resection without sacrificing lung parenchyma has only been summarized in case reports or in studies involving a limited sample size (12,24-26). Regnard et al. reviewed 65 cases of carinal surgeries for malignancies spanning 19 years and found that only 5 patients underwent carinal resection without lung resection (10). Mitchell et al. summarized 60 cases of carinal resections for bronchogenic carcinoma, of which only 18 cases were isolated carinal resections (11). Stamatis et al. focused on carinal resection with lung parenchyma preservation but only included 19 patients in their study (12). In our study, carinal resection and reconstruction with 
Table 4 Risk factors associated with postoperative complications after carinal resection and reconstruction with complete pulmonary parenchyma preservation

\begin{tabular}{|c|c|c|c|c|}
\hline Factors & \multicolumn{2}{|c|}{ Univariate analysis } & \multicolumn{2}{|c|}{ Multivariate analysis } \\
\hline \multicolumn{5}{|l|}{ Sex } \\
\hline Male & $0.833(0.218-3.190)$ & 0.790 & & \\
\hline Female & REF & & & \\
\hline \multicolumn{5}{|l|}{ BMI } \\
\hline Underweight & $0.917(0.051-16.494)$ & 0.953 & $0.368(0.016-8.277)$ & 0.529 \\
\hline Overweight & $0.092(0.010-0.838)$ & 0.034 & $0.092(0.009-0.922)$ & 0.042 \\
\hline Normal weight & REF & & REF & \\
\hline Diabetes & NA & $>0.99$ & & \\
\hline Coronary heart disease & NA & $>0.99$ & & \\
\hline Cerebral infarction & NA & $>0.99$ & & \\
\hline Deep vein thrombosis & NA & $>0.99$ & & \\
\hline Previous lung surgery & $0.487(0.046-5.215)$ & 0.552 & & \\
\hline Obstructive pneumonia or atelectasis & $0.750(0.118-4.760)$ & 0.760 & & \\
\hline Preoperative endoscopic treatment & NA & $>0.99$ & & \\
\hline \multicolumn{5}{|l|}{ Approach } \\
\hline Release of hilar or ligament & $0.205(0.022-1.927)$ & 0.209 & & \\
\hline Anastomosis wrapped & $0.750(0.118-4.760)$ & 0.760 & & \\
\hline \multicolumn{5}{|l|}{ Type of reconstruction } \\
\hline Double-barrel reconstruction/first type of Eschapasse reconstruction & REF & & & \\
\hline Second type of Eschapasse reconstruction/Barclay reconstruction & $1.167(0.269-5.054)$ & 0.837 & & \\
\hline Blood loss (mL) & $0.994(0.987-1.002)$ & 0.123 & $0.996(0.988-1.003)$ & 0.267 \\
\hline Operation duration (min) & $0.995(0.983-1.007)$ & 0.427 & & \\
\hline The length of resected airway & $0.978(0.561-1.706)$ & 0.938 & & \\
\hline \multicolumn{5}{|l|}{ Margins } \\
\hline Positive & $3.333(0.717-15.506)$ & 0.125 & $3.090(0.533-17.899)$ & 0.208 \\
\hline Negative & REF & & REF & \\
\hline
\end{tabular}

$\mathrm{BMI}$, body mass index; $\mathrm{Cl}$, confidence interval; HFJV, high-frequency jet ventilation; ECMO, extracorporeal membrane oxygenation; NA, not available; OR, odds ratio; REF, reference. 
Table 5 Histological examination of patients receiving carinal resection and reconstruction with complete pulmonary parenchyma preservation

\begin{tabular}{|c|c|}
\hline Variables & Overall $(n=36)$ \\
\hline \multicolumn{2}{|l|}{ Pathology } \\
\hline Squamous cell carcinoma & $12(33.3)$ \\
\hline Adenoid cystic carcinoma & $15(41.7)$ \\
\hline Mucoepidermoid carcinoma & $2(5.6)$ \\
\hline Atypical carcinoid & $1(2.8)$ \\
\hline Stricture & $1(2.8)$ \\
\hline Others $^{\dagger}$ & 5 (13.9) \\
\hline Tumor size $(\mathrm{cm})^{\ddagger}$ & $2.6 \pm 1.2$ \\
\hline \multicolumn{2}{|l|}{ Margin $^{\ddagger}$} \\
\hline Negative & $14(40.0)$ \\
\hline Positive & $21(60.0)$ \\
\hline The length of resected airway $(\mathrm{cm})^{\star}$ & $3.2 \pm 1.2$ \\
\hline For negative margins ${ }^{\ddagger}$ & $3.0 \pm 1.6$ \\
\hline For positive margins & $3.3 \pm 1.2$ \\
\hline \multicolumn{2}{|l|}{ Lymph node status $^{\ddagger}$} \\
\hline NO & $29(82.9)$ \\
\hline $\mathrm{N} 1$ & $2(5.7)$ \\
\hline $\mathrm{N} 2$ & $4(11.4)$ \\
\hline
\end{tabular}

Values are presented as $\mathrm{n}(\%)$ or mean \pm standard deviation. ${ }^{\dagger}$, other pathological diagnoses included schwannoma $(n=1,2.8 \%)$, leiomyoma ( $n=1,2.8 \%)$, inflammatory myofibroblastic tumor $(n=1,2.8 \%)$, and atypical hyperplasia $(n=2,5.6 \%) ;{ }^{\ddagger}$, one case of stricture was excluded from analysis; ${ }^{*}$, no significant difference was detected in the length of resected airway between $\mathrm{R} 0$ and $R 1$ resections $(P=0.559)$ by Student's $t$-test.

complete pulmonary parenchyma preservation was reviewed in a relatively larger sample size over a period of 14 years.

Generally, the mortality and morbidity rate after carinal resection were $3-20 \%$ and $11-50 \%$ as reported, respectively (16). The postoperative complications after carinal resection and reconstruction commonly include acute respiratory distress syndrome, pneumonia, etc. in the early stage, while anastomotic fistula, stenosis, local tumor recurrence, etc. in the late stage. In our study, the operative mortality rate was $5.6 \%$, while the morbidity rate was $38.9 \%$. Few studies have explored the risk factors for postoperative complications after carinal resection. With the largest sample size of carinal surgeries to date, Mitchell et al. reported that the main risk factors for postoperative death were postoperative mechanical ventilation, the extent of resected airway, and development of anastomotic complications (27). Costantino et al. reviewed carinal surgeries performed at Massachusetts General Hospital over 2 decades and found complications were significantly associated with preoperative chemotherapy, radiation, and concomitant pulmonary resection (13). However, the factors affecting the complications after isolated carinal resection have not yet been analyzed.

In this study, BMI was identified as an independent predictor of postoperative complications, with higher BMI associated with a lower incidence of postoperative events ( $\mathrm{P}=0.042, \mathrm{OR}=0.092,95 \% \mathrm{CI}: 0.009-0.922)$. Although it seems intuitive that obesity might lead to poor perioperative outcomes $(28,29)$, several studies have revealed that no significant difference could be detected between normal weight and overweight patients in operative mortality and morbidity after lung resection (30). Further, Williams et al. found that compared to patients of a normal weight, those who were overweight or mild to moderately obese had a lower risk of postoperative events after lung surgery (31). Similarly, research by Mungo et al. showed no increase in operative mortality and morbidity among obese patients, but overweight and mildly obese patients had a shorter hospital stay. These results might have been due to a positive effect of obesity on the body's ability to mount an appropriate inflammatory response to the stress of undergoing an operation (32).

The median survival time of the whole cohort was 107 months. The OS rate was $94.4 \%$ at 1 year and $79.7 \%$ at 5 years, which was considerable and a promising result. Several studies on carinal resection revealed that N2 lymph node metastasis and positive resected margins impaired the oncological prognosis $(8,13,33,34)$. As for lesions involving the carina, with fewer cases of lymph node metastasis included, $\mathrm{R} 1$ resection was identified as an independent risk factor for survival in this study $(\mathrm{P}=0.042, \mathrm{HR}=4.938$, 95\% CI: 1.062-22.950), which was consistent with survival outcomes reported by Stamatis et al. who found that all patients who underwent complete resection remained alive during the follow-up time, while 3 in 5 patients with positive resected margins died due to recurrence (12).

Typically, surgical margin is related to the extent of resection, and anastomotic tension is increased when more airway is resected, potentially leading to ischemia at the anastomosis, scar formation, and eventually stenosis (16). However, in the present study, the length of resected 


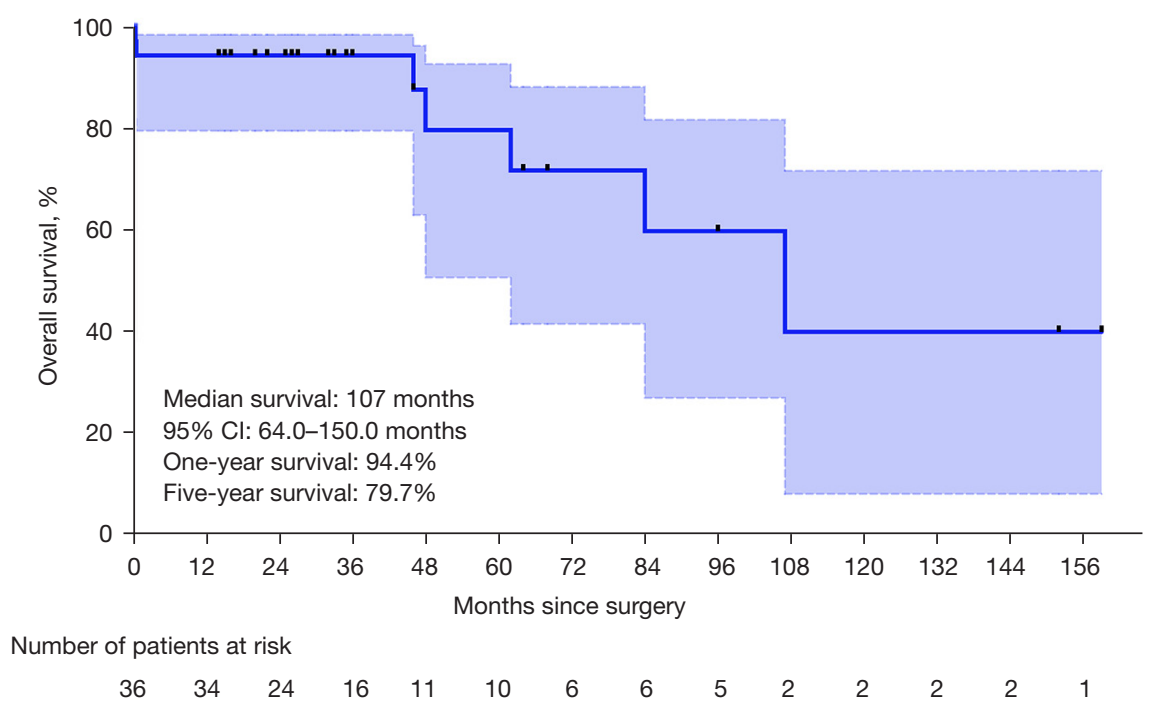

Figure 2 Overall survival of patients receiving carinal resection and reconstruction with complete pulmonary parenchyma preservation. The shaded area shows the $95 \%$ confidence interval.

airway was similar for $\mathrm{R} 0$ and $\mathrm{R} 1$ resections $(\mathrm{P}=0.559)$. In some cases, complete resection for malignancies was rarely realized, particularly for ACC which was characterized by a high positive resected margin rate in this study $(80 \%)$. Postoperative adjuvant radiotherapy could help improve prognosis and achieve oncological outcomes similar to complete resection $(35,36)$. In the present study, all SCC patients with positive margins were in an older age range (55-70 years) and with poor pulmonary function, they would likely be unable to tolerate an extended resection. Thus, for carinal resection and reconstruction, in addition to meticulous multidisciplinary preoperative evaluations, surgical expertise and dedicated perioperative management, a rigorous individual evaluation of perioperative risks is also necessary to determine whether to perform an incomplete resection followed by adjuvant therapy rather than an extended resection such as carinal sleeve pneumonectomy.

This study had several limitations. As a retrospective study, there were inevitable biases. Although this study included a relatively larger population than most previous research on carinal resection and reconstruction with pulmonary parenchyma preservation, it was still limited by the sample size, and risk factors for survival could not be evaluated by multivariate analysis. Enlargement of the sample size or a study of carinal surgeries involving multiple institutions would rectify these issues.

\section{Conclusions}

For malignancies involving tracheobronchial bifurcation or benign diseases such as stricture, carinal resection and reconstruction with complete pulmonary parenchyma preservation in selected patients was feasible to achieve an appreciable long-term survival at the risk of acceptable operative mortality and morbidity, particularly when complete resection with negative margins could be realized. 


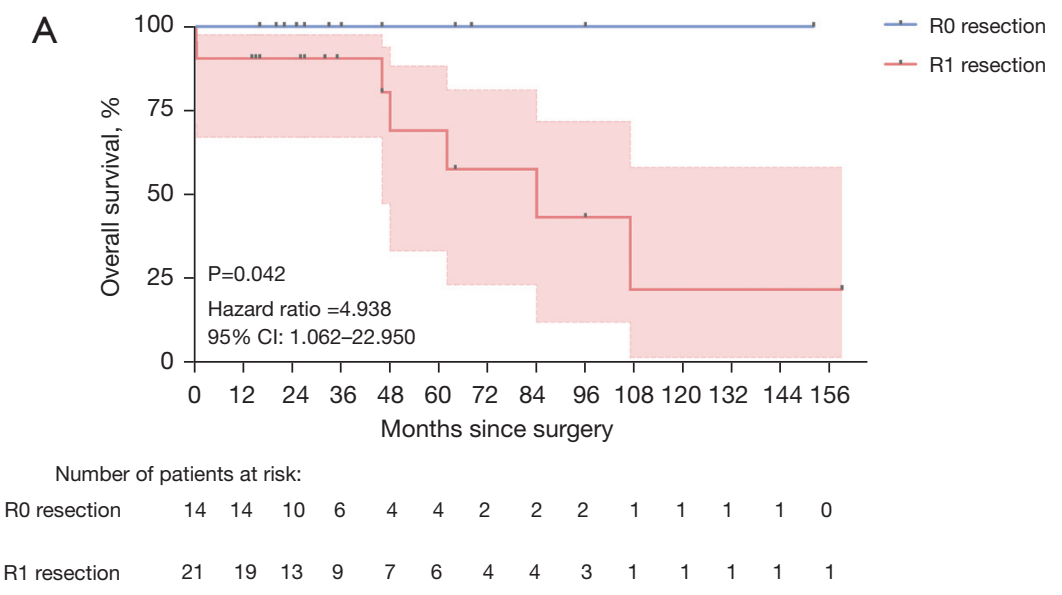

B

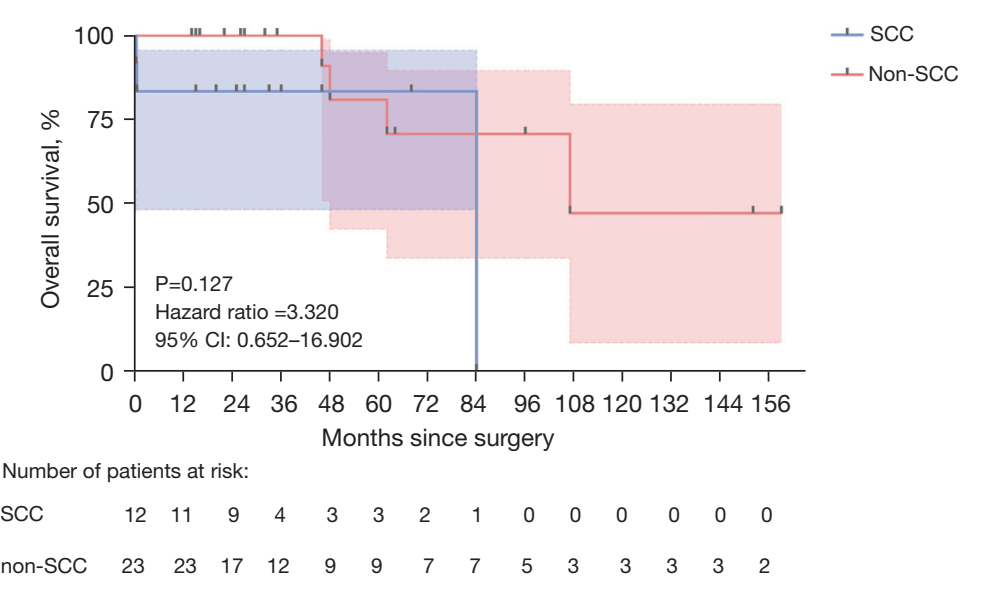

Figure 3 Overall survival of patients receiving carinal resection and reconstruction with complete pulmonary parenchyma preservation was compared between R0 and R1 resections (A), and between SCC and non-SCC (B). The shaded area shows the 95\% confidence interval. SCC, squamous cell carcinoma.

\section{Acknowledgments}

The authors appreciate the academic support from the AME Thoracic Surgery Collaborative Group.

Funding: None.

\section{Footnote}

Reporting Checklist: The authors have completed the STROBE reporting checklist. Available at https://dx.doi. org/10.21037/tlcr-21-937

Data Sharing Statement: Available at https://dx.doi. org/10.21037/tlcr-21-937

Conflicts of Interest: All authors have completed the ICMJE uniform disclosure form (available at https://dx.doi. org/10.21037/tlcr-21-937). The authors have no conflicts of interest to declare.

Ethical Statement: The authors are accountable for all aspects of the work in ensuring that questions related to the accuracy or integrity of any part of the work are appropriately investigated and resolved. The study was conducted in accordance with the Declaration of Helsinki (as revised in 2013). The study was approved by the ethics board of Shanghai Chest Hospital (ethics approval: KS1992) and individual consent for this retrospective analysis was waived.

Open Access Statement: This is an Open Access article 
distributed in accordance with the Creative Commons Attribution-NonCommercial-NoDerivs 4.0 International License (CC BY-NC-ND 4.0), which permits the noncommercial replication and distribution of the article with the strict proviso that no changes or edits are made and the original work is properly cited (including links to both the formal publication through the relevant DOI and the license). See: https://creativecommons.org/licenses/by-nc-nd/4.0/.

\section{References}

1. Schweiger T, Hoetzenecker K, Prosch H, et al. Progressive Stenosis of Both Main Bronchi Associated With Recurrent Infections of a Carinal Pouch. Ann Thorac Surg 2018;105:e1-3.

2. Liu XY, Liu FY, Wang Z, et al. Management and surgical resection for tumors of the trachea and carina: experience with 32 patients. World J Surg 2009;33:2593-8.

3. Xu Y, Guo Z, Liu R, et al. Bioengineered carina reconstruction using In-Vivo Bioreactor technique in human: proof of concept study. Transl Lung Cancer Res 2020;9:705-12.

4. Chambers A, Routledge T, Billè A, et al. Does surgery have a role in T4N0 and T4N1 lung cancer? Interact Cardiovasc Thorac Surg 2010;11:473-9.

5. Yamanashi K, Menju T, Hamaji M, et al. Prognostic factors related to postoperative survival in the newly classified clinical T4 lung cancer. Eur J Cardiothorac Surg 2020;57:754-61.

6. Yamamoto K, Miyamoto Y, Ohsumi A, et al. Surgical results of carinal reconstruction: an alterative technique for tumors involving the tracheal carina. Ann Thorac Surg 2007;84:216-20.

7. Jiang F, Xu L, Yuan F, et al. Carinal resection and reconstruction in surgical treatment of bronchogenic carcinoma with carinal involvement. J Thorac Oncol 2009;4:1375-9.

8. Yamamoto K, Miyamoto Y, Ohsumi A, et al. Results of surgical resection for tracheobronchial cancer involving the tracheal carina. Gen Thorac Cardiovasc Surg 2007;55:231-9; discussion 238-9.

9. Shin S, Park JS, Shim YM, et al. Carinal resection and reconstruction in thoracic malignancies. J Surg Oncol 2014;110:239-44.

10. Regnard JF, Perrotin C, Giovannetti R, et al. Resection for tumors with carinal involvement: technical aspects, results, and prognostic factors. Ann Thorac Surg 2005;80:1841-6.

11. Mitchell JD, Mathisen DJ, Wright CD, et al. Resection for bronchogenic carcinoma involving the carina: long-term results and effect of nodal status on outcome. J Thorac Cardiovasc Surg 2001;121:465-71.

12. Stamatis G, Fechner S, Rocha M, et al. Resection of the Tracheobronchial Bifurcation With Complete Preservation of Lung Parenchyma. Ann Thorac Surg 2017;104:1741-7.

13. Costantino CL, Geller AD, Wright CD, et al. Carinal surgery: A single-institution experience spanning 2 decades. J Thorac Cardiovasc Surg 2019;157:2073-2083.e1.

14. Orlowski TM, Dziedzic D. Carinal Resection and Reconstruction. Thorac Surg Clin 2018;28:305-13.

15. Gonfiotti A, Jaus MO, Barale D, et al. Carinal resection. Thorac Surg Clin 2014;24:477-84.

16. Tapias LF, Ott HC, Mathisen DJ. Complications Following Carinal Resections and Sleeve Resections. Thorac Surg Clin 2015;25:435-47.

17. Lanuti M, Mathisen DJ. Carinal resection. Thorac Surg Clin 2004;14:199-209.

18. Hu D, Wang Z, Tantai J, et al. Robotic-assisted thoracoscopic resection and reconstruction of the carina. Interact Cardiovasc Thorac Surg 2020;31:912-4.

19. Shamji FM. Factors Favoring and Impairing Healing of Tracheal Anastomosis. Thorac Surg Clin 2018;28:211-8.

20. Watanabe $Y$, Mine S, Tsurumaru M, et al. Carinal resection and double-barrel reconstruction following oesophagectomy for oesophageal carcinoma with bronchooesophageal fistula. Interact Cardiovasc Thorac Surg 2021;32:489-91.

21. Campisi A, Ciarrocchi AP, Congiu S, et al. Sleeve Lobectomy: To Wrap or Not to Wrap the Bronchial Anastomosis? Ann Thorac Surg 2022;113:250-5.

22. Kamiyoshihara M, Nagashima T, Igai H, et al. Videoassisted thoracic lobectomy with bronchoplasty for lung cancer, with special reference to methodology. Interact Cardiovasc Thorac Surg 2011;12:534-8.

23. Oliveros E, Somers VK, Sochor O, et al. The concept of normal weight obesity. Prog Cardiovasc Dis 2014;56:426-33.

24. Hoseok I, Joungho H, Ahn KM, et al. Complete surgical resection of inflammatory myofibroblastic tumor with carinal reconstruction in a 4-year-old boy. J Pediatr Surg 2005;40:e23-5.

25. Grillo HC, Bendixen HH, Gephart T. Resection of the carina and lower trachea. Ann Surg 1963;158:889-93.

26. Betser L, De Wolf J, Glorion M, et al. Use of 3-dimensional computed tomography for planning a complex sleeve bronchoplasty with total parenchyma-sparing resection of a carcinoid tumour in the right main bronchus. Interact 
Cardiovasc Thorac Surg 2019;29:638-40.

27. Mitchell JD, Mathisen DJ, Wright CD, et al. Clinical experience with carinal resection. J Thorac Cardiovasc Surg 1999;117:39-52; discussion 52-3.

28. Petrella F, Radice D, Borri A, et al. The impact of preoperative body mass index on respiratory complications after pneumonectomy for non-small-cell lung cancer. Results from a series of 154 consecutive standard pneumonectomies. Eur J Cardiothorac Surg 2011;39:738-44.

29. Madill J, Gutierrez C, Grossman J, et al. Nutritional assessment of the lung transplant patient: body mass index as a predictor of 90-day mortality following transplantation. J Heart Lung Transplant 2001;20:288-96.

30. Dhakal B, Eastwood D, Sukumaran S, et al. Morbidities of lung cancer surgery in obese patients. J Thorac Cardiovasc Surg 2013;146:379-84.

31. Williams T, Gulack BC, Kim S, et al. Operative Risk for Major Lung Resection Increases at Extremes of Body Mass Index. Ann Thorac Surg 2017;103:296-302.

Cite this article as: Chen $\mathrm{L}$, Wang $\mathrm{Z}$, Zhao $\mathrm{H}$, Maurizi G, Miyazaki T, Waseda R, Yao F. Carinal resection and reconstruction with complete pulmonary parenchyma preservation: a single-institution analysis of 36 cases. Transl Lung Cancer Res 2021;10(12):4526-4537. doi: 10.21037/tlcr21-937
32. Mungo B, Zogg CK, Hooker CM, et al. Does obesity affect the outcomes of pulmonary resections for lung cancer? A National Surgical Quality Improvement Program analysis. Surgery 2015;157:792-800.

33. Sezen CB, Kocaturk CI, Bilen S, et al. Long-Term Outcomes of Carinal Sleeve Resection in Non-Small Cell Lung Cancer. Thorac Cardiovasc Surg 2020;68:190-8.

34. Lin H, Lu Y, Gu T, et al. Influence of nodal status on the surgical outcome for bronchogenic carcinoma involving the carina: a systematic review and meta-analysis. Minerva Chir 2018;73:497-504.

35. Yang H, Yao F, Tantai J, et al. Resected Tracheal Adenoid Cystic Carcinoma: Improvements in Outcome at a Single Institution. Ann Thorac Surg 2016;101:294-300.

36. Wang Y, Cai S, Gao S, et al. Tracheobronchial Adenoid Cystic Carcinoma: 50-Year Experience at the National Cancer Center, China. Ann Thorac Surg 2019;108:873-82.

(English Language Editor: A. Muylwyk) 